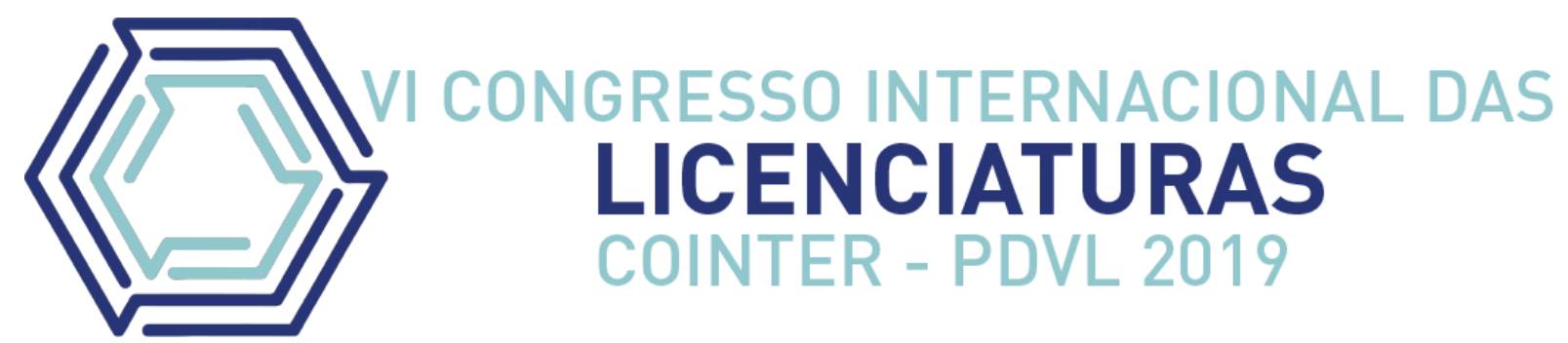

\title{
O USO DE METODOLOGIAS ATIVAS COMO FERRAMENTAS PARA PROMOVER O APRENDIZADO DOS CONTEÚDOS DE QUÍMICA NO ENSINO TÉCNICO
}

\author{
EL USO DE METODOLOGÍAS ACTIVAS COMO HERRAMIENTAS PARA \\ PROMOVER EL APRENDIZAJE DE LA QUÍMICA EN LA EDUCACIÓN TÉCNICA
}

\section{THE USE OF ACTIVE METHODOLOGIES AS TOOLS TO PROMOTE CHEMICAL LEARNING IN TECHNICAL EDUCATION}

\author{
Apresentação: Comunicação Oral \\ Daniela de Lima Santos ${ }^{1}$; Thalita Arthur ${ }^{2}$; Carlos Fernando Barboza da Silva ${ }^{3}$; Ana Carla \\ Dantas Midões ${ }^{4}$
}

\section{DOI: https://doi.org/10.31692/2358-9728.VICOINTERPDVL.2019.0066}

\section{Resumo}

Este projeto de pesquisa buscou trabalhar momentos pedagógicos com os alunos do ensino médio do ensino técnico em química com aplicação de algumas abordagens pedagógicas ativas como: o estudo de caso, a elaboração de jogos didáticos e atividades lúdicas, a aprendizagem em espaço não formal como a visita técnica e a experimentação investigativa. O trabalho nasceu com a proposta de trabalho de final do curso de licenciatura em química com o intuito da formação inicial de professores que pesquisam a própria prática e a reflexão sobre o trabalho desenvolvido em sala de aula. Abordando um problema local de descarte de lixo no espaço de vivência da escola, onde foi realizado o estágio supervisionado obrigatório, a partir da problematização inicial, foi estruturado um estudo de caso abordando a importância do descarte correto do lixo escolar. As atividades posteriores seguiram a linha temática para as outras atividades didáticas sendo elas as atividades lúdicas, a experimentação investigativa e a visita técnica. As atividades foram desenvolvidas durante todo o ano letivo da primeira série do ensino médio técnico. O objetivo deste projeto foi verificar como a aprendizagem ocorre por meio do uso de metodologias ativas de ensino, e considerando que o uso de metodologias alternativas é um fator decisivo na aprendizagem, é que este tema é muito discutido e ainda há uma necessidade de comprovar com a realização de pesquisas baseadas em hipóteses, fundamentação teórica e metodológica e tratamento e análise de dados que essas técnicas apresentam grande potencial de êxito no processo da aprendizagem dos alunos.

\footnotetext{
1 Licenciatura em Química, Instituto Federal de Educação, Ciência e Tecnologia de São Paulo Câmpus Capivari, daniellaelide@ifspcapivari.com.br

${ }^{2}$ Mestre Instituto Federal de Educação, Ciência e Tecnologia de São Paulo Câmpus Capivari, thalitaarthur@ifsp.edu.br;

${ }^{3}$ Doutor, Instituto Federal de Educação, Ciência e Tecnologia de São Paulo Câmpus Capivari, cfbsilva@ifsp.edu.br

${ }^{4}$ Mestre Instituto Federal de Educação, Ciência e Tecnologia de São Paulo Câmpus Capivari, anacarladantas@ifsp.edu.br
} 
Palavras-Chave: Ensino de química, Momentos pedagógicos, Aprendizagem, Metodologias ativas.

\begin{abstract}
Resumen
Este proyecto de investigación buscó trabajar en momentos pedagógicos con estudiantes de secundaria en educación técnica en química con la aplicación de algunos enfoques pedagógicos activos tales como: estudio de caso, elaboración de juegos didácticos y actividades lúdicas, aprendizaje no formal como visita técnica y experimentación investigativa. El trabajo nació con el trabajo propuesto al final de la licenciatura en química con el propósito de la formación inicial de maestros que investigan su propia práctica y la reflexión sobre el trabajo desarrollado en el aula. Al abordar un problema local de eliminación de desechos en el espacio habitable de la escuela, donde se realizó la pasantía supervisada obligatoria, desde la problematización inicial, se estructura un estudio de caso que aborda la importancia de la eliminación correcta de los desechos escolares. Las actividades posteriores siguieron la línea temática para las otras actividades didácticas, que fueron las actividades lúdicas, la experimentación investigativa y la visita técnica. Las actividades se desarrollaron durante todo el año escolar del primer grado de secundaria técnica. El objetivo de este proyecto fue verificar cómo se produce el aprendizaje mediante el uso de metodologías de enseñanza activas, y teniendo en cuenta que el uso de metodologías alternativas es un factor decisivo en el aprendizaje, es que este tema es muy discutido y aún hay que demostrarlo con realizando investigaciones basadas en hipótesis, fundamentos teóricos y metodológicos y tratamiento y análisis de datos de que estas técnicas tienen un gran potencial para el éxito en el proceso de aprendizaje de los estudiantes.
\end{abstract}

Palabras Clave: Enseñanza de la química, Momentos pedagógicos, Aprendizaje, Metodologías activas.

\begin{abstract}
This research project sought to work on pedagogical moments with high school students in technical education in chemistry with the application of some active pedagogical approaches such as: case study, the elaboration of didactic games and playful activities, non-formal learning as technical visit and investigative experimentation. The work was born with the proposed work of the end of the teacher formation course in chemistry with the purpose of the initial formation of teachers who research their own practice and the reflection on the work developed in the classroom. Addressing a local problem of waste disposal in the school living space, where the mandatory supervised internship was performed, from the initial problematization, a case study was structured addressing the importance of the correct disposal of school waste. Subsequent activities followed the thematic line for the other didactic activities, which were the playful activities, the investigative experimentation and the technical visit. The activities were developed throughout the school year of the first grade of technical high school. The objective of this project was to verify how learning occurs through the use of active teaching methodologies, and considering that the use of alternative methodologies is a decisive factor in learning, it is that this topic is much discussed and there is still a need to prove with conducting research based on hypotheses, theoretical and methodological foundation and treatment and data analysis that these techniques have great potential for success in the learning process of students.
\end{abstract}


Keywords: Chemistry teaching, Pedagogical moments, Learning, Active methodologies.

\section{Introdução}

Em busca de metodologias que facilitem o ensino de ciências alguns educadores têm trabalhado com momentos pedagógicos alternativos ao método tradicional com seus alunos para facilitar o ensino de química. Este projeto de pesquisa trabalhou com quatro tipos de abordagens metodológicas que foram divididas em quatro momentos pedagógicos. Tendo em vista que hipóteses foram levantadas a respeito das abordagens metodológicas: Como verificar se os alunos aprendem com resolução de problemas? Como aprender o conteúdo de misturas homogênea e heterogênea pesquisando, criando e brincando? Como os alunos aprendem por meio da experimentação investigativa? É possível aprender em espaços não formais de ensino?

O trabalho desenvolvido durante a última etapa do curso de formação inicial de professores no curso de licenciatura em química visou a formação do professor pesquisador e reflexivo. A pesquisa na formação de professores tem sido defendida por vários autores como estratégia de melhoria do trabalho docente e no entendimento de como se dá a aprendizagem de alunos na escola. Segundo Diniz-Pereira (2008), o movimento dos educadorespesquisadores tem o potencial de se transformar em um movimento contra hegemônico global, articulando experiências que buscam a construção de modelos críticos de formação de professores. Charlot (2002) relata que é muito difícil formar professores sem termos uma definição precisa de seu trabalho e centra seu trabalho em três pontos: pergunta-se a razão pela qual a pesquisa educacional não entrar na sala de aula, a questão da relação entre a teoria e a prática e sobre as relações entre as práticas dos alunos. Segundo o autor, existe um afastamento muito importante entre a sala de aula e a pesquisa educacional e que o papel da pesquisa é forjar ferramentas para melhor entender o que está acontecendo na sala de aula e criar inteligibilidade para melhor entender o que está acontecendo ali. O professor que decide como agir no cotidiano e na situação contextualizada que estiver vivendo. Charlot (2002) acredita que não exista um problema de diálogo entre teoria e prática, o que existe é um problema de diálogo entre dois tipos de teoria: uma teoria enraizada nas práticas e uma teoria que está se desenvolvendo na área da pesquisa e das próprias ideias entre os pesquisadores. Relata ainda, a importância de se focar na prática do aluno e não na prática do professor, se o aluno não fizer o trabalho intelectual, não vai aprender, vai fracassar. O trabalho do professor não é ensinar, é fazer o aluno aprender. E o que importa saber é se o trabalho do professor ajuda o aluno a desenvolver uma atividade intelectual e qual é o sentido dessa situação para o aluno. 
Devido à formação do professor pesquisador/reflexivo e o uso de metodologias ativas serem fatores decisivos na aprendizagem, é que esses temas vem sendo muito discutido nos encontros de ensino de química, e por isso ainda há uma necessidade de comprovar por meio de mais dados que essa visão de formação de professores e o modo como são trabalhados os temas em sala de aula tem apresentado êxito no processo da aprendizagem dos alunos.

\section{Fundamentação Teórica}

Historicamente, a experimentação em ciências foi intensificada com o empirismo na idade moderna. Antoine Lavoisier em seu tratado propôs que existia na combustão uma matéria que compunha o ar. Essa matéria determinava a ocorrência da reação de queima derrubando assim a teoria do flogístico proposta pelo médico e químico Stahl. Outro filósofo que se destacou nessa época foi Proust que conseguiu distinguir claramente as misturas dos compostos. Diversos experimentos foram realizados por Lavoisier sendo estes a redução dos óxidos aos seus respectivos metais e a síntese e a decomposição da água. Deste modo, somente nas últimas décadas do século 19, foram que países, como Inglaterra e Estados Unidos, começaram a pensar no ensino de ciências e as experimentações foram inseridas no currículo de ciências das suas escolas.

No Brasil, a experimentação começou a ter sentido ainda no século 19, devido à necessidade socioeconômica do país na época. Neste período precisava de mãos de obras capazes de manipular a extração e a transformação dos minérios em metais, foi então que os portugueses começaram a introduzir a experimentação no ensino de ciência na escola, porém de forma utilitarista (SILVA, 2010). No entanto, a consolidação da experimentação como estratégia de ensino passou a ter um significado importante nas escolas na segunda metade do século 20, pois ocorreu a consolidação dos colégios de aplicação e neste período, em 1938, foi criado o Instituto Nacional de Estudos e Pesquisa Educacionais Anísio Teixeira (INEP), assim como a criação da CBPE-Centro Brasileiro de Pesquisas Educacionais, em 1955 (SILVA, 2010).

Existem obstáculos à introdução da experimentação no ensino de ciências dentro de algumas escolas, por isso que alguns educadores têm se queixado, já que não há laboratórios de química adequados nas escolas. Peron (2016), acreditam que por esses e outros motivos alguns docentes deixam de inserir aulas experimentais como complemento para as aulas teóricas.

Em vista disto, temos como referenciais autores que trabalham com linha temática experimentação no ensino, pois defendem a experimentação no ensino de química. Dentre 
alguns dos principais autores, podemos citar o Chassot (2007), que afirma que uma das formas de tornar o imaginário real é por meio da experimentação no ensino de ciências. O outro autor a ser citado é Peron (2016) que, segundo ele, este modelo de ferramenta se for empregado corretamente, auxilia os alunos a terem interesse pela aprendizagem dentro de sala de aula de ciências. Outra que concorda com isso é Schnetzler (2010) que afirma que para aprender conteúdos como os íons, átomos e moléculas, partículas em movimento a nível microscópico é algo complexo para o aluno. Nesse sentido, o docente precisa fazer uma adaptação no ensino tradicional, incrementado um pouco de aulas experimentais para facilitar a aprendizagem dos educandos. De acordo Giordan (1999), a introdução de aulas experimentais no ensino de Química pode aumentar o nível de aprendizagem dos alunos. O aluno irá relacionar o experimento com o que ele já viu da teoria, por meio da observação, coleta de dados, registros e conclusão. E dessa forma o autor acredita que a experimentação auxiliar na aprendizagem destes alunos.

Em busca de metodologias que facilitem o ensino de ciências alguns educadores têm trabalhado alguns momentos pedagógicos com seus alunos para facilitar o ensino de química. Por exemplo, o estudo de caso é um tipo de abordagem metodológica usada no ensino de química, que permite que um grupo de estudantes aprenda por meio de um problema que o educador apresenta e espera que eles proponham soluções.

O método de Estudo de Casos é uma variante do método Aprendizagem Baseada em Problemas (ABP), sendo uma metodologia que possibilita aos educandos direcionarem sua própria aprendizagem com a mediação do educador, contribuindo no desenvolvimento da capacidade de tomada de decisão dos alunos e da habilidade de resolver problemas, no aperfeiçoamento da comunicação oral e escrita, assim como na aprendizagem sobre os conceitos envolvidos na disciplina de Química (SÁ e QUEIROZ, 2010).

Segundo Pierine (2015), a Aprendizagem Baseada em Problemas (ABP), assim como a Aprendizagem Baseada em Casos Investigativos (Case Study ou Estudo de Casos) são também estratégias pedagógicas que enfatizam o aprendizado dos alunos mediado pelo professor. $\mathrm{O}$ aluno nesse sentido como protagonista da sua própria aprendizagem.

Existe certa preocupação com a aprendizagem dos alunos e por isso que se faz necessário repensar o ensino de Química, que é muito centrado em teorias e cálculos, despertando pouco interesse nos alunos. O conceito de atividades lúdicas neste caso está relacionado com o ludismo, ou seja, atividade relacionadas com jogos e com o ato de brincar. 
Outra abordagem metodológica bastante utilizada pelos educadores são as atividades lúdicas, que neste sentido estimulam os alunos a participarem das aulas e facilitam a aprendizagem. A utilização de jogos e atividades lúdicas no ensino de ciências é muito empregada na educação brasileira, em todos os níveis do ensino básico (LIMA, 2018).

Esquiller (2015), cita a afirmação de Cunha a respeito da importância do desenvolvimento dos jogos como recurso didático nas escolas.

Os jogos são indicados como um tipo de recurso didático educativo que podem ser utilizados em momentos distintos, como na apresentação de um conteúdo, ilustração de aspectos relevantes ao conteúdo, como revisão ou síntese de conceitos importantes e avaliação de conteúdos já desenvolvidos (CUNHA; 2004).

Segundo Cunha (2004), os jogos são uma boa indicação, para serem usados como instrumentos que auxiliam tanto professores quanto alunos na construção do conhecimento, sendo uma ferramenta fundamental para servir como guia no processo de ensino por parte do professor e aprendizagem por parte dos alunos, dentro da sala de aula, pois contribuem para construírem novas descobertas, desenvolvem e enriquecem a criatividade, personalidade e intelecto dos alunos.

É essencial que os docentes promovem entre os alunos uma metodologia de ensino diferenciada, prazerosa e motivadora, que também fortaleçam o trabalho em equipe dentro da sala de aula.

Estudos e pesquisas vêm mostrando que o ensino de Química tem sido executado no formato bancário, na maioria das vezes, o ensino se realiza pela metodologia da memorização e reprodução de nomes, fórmulas e cálculos. Muitos estudantes têm certa dificuldade de entender certos conteúdos trabalhados em aulas de Química, por não conseguirem relacionar o conteúdo químico com o cotidiano (MACEDO, 2012).

O uso do lúdico como ferramenta no ensino de química é algo primordial para tornar o ensino mais prazeroso. O jogo possui dois tipos de elementos que são o prazer e o esforço espontâneo, que sempre é acompanhado do fator afetivo e do fator social. Por ser considerado um tipo de atividade lúdica, o jogo no ensino de química possui duas funções a lúdica e educativa. A parte lúdica está no prazer da brincadeira, enquanto que a parte educativa se concretiza no momento de manipular o jogo, sendo nesse instante que o aprendizado acontece. São essas atividades metodológicas que permitem uma boa exploração do ambiente e proporciona uma maior abordagem dos conteúdos do currículo escolar da instituição de ensino 
(GIORDAN, 1999).

O uso dos experimentos ou metodologias como mecanismos que oferecem suporte no processo de ensino aprendizagem têm sido bastante adotados por docentes, principalmente no ensino de química, como um meio facilitador da aprendizagem (FRANCISCO JR, 2008).

Por exemplo, a experimentação investigativa não segue uma "receita de um bolo" como é conhecida a experimentação tradicional, metodologia bastante utilizada nas poucas escolas que possui laboratório de química. Sabe-se que este tipo de experimentação investigativa permite que o aluno participe como um solucionador de problema, isso possibilita preparar este aluno para ser um cidadão atuante na sociedade no qual ele se encontra (SOUZA, 2013).

Outra metodologia muito utilizada no meio escolar são as atividades em espaços não formais. As instituições de ensino buscam, por meio de visitas técnicas, colocar o aluno mais próximo das empresas, indústrias, parques, museus e etc. Por isso, que a visita tem sido mais uma ferramenta que permite ao aluno em fase de formação escolar conhecer na prática aquilo que eles aprendem em sala de aula. Para Costa e Araujo (2012), a visita técnica tem papel fundamental para contribuir com os futuros profissionais, mostrando sua importância para a formação de indivíduos que se portem de maneira crítica dentro da sociedade.

Acreditamos que a visita técnica deve ser formulada de acordo com o tema em estudo, ou seja, em concordância com o planejamento das disciplinas, como as disciplinas técnicas de laboratório e química, relacionando-se com os objetivos dos educadores para que realmente ocorresse o aprendizado por parte dos alunos sobre os conceitos de mistura, técnicas de separação de misturas, tipos de misturas e etapas do tratamento da água.

E é por acreditar que o uso de metodologias alternativas é um fator decisivo na aprendizagem, é que este tema é discutido nos encontros de ensino de química, por isso ainda há uma necessidade de comprovar por meio de mais dados que essa técnica tem dado êxito no processo da aprendizagem dos alunos.

Nesse sentido, o objetivo deste projeto foi promover a aprendizagem significativa e verificar se metodologias ativas como: o uso do espaço formal de ensino (visita técnica), os jogos didáticos, os estudos de caso e as experimentações investigativas; promovem o aprendizado dos conteúdos ministrados com os alunos do ensino médio.

\section{Metodologia}

Os encontros com a turma $\mathrm{A}$ e $\mathrm{B}$, foram divididos em quatros momentos. Estes 
momentos foram importantes para verificar as hipóteses levantadas sobre o uso dessas metodologias ativas no ensino de química.

Primeiro momento pedagógico

No primeiro momento, buscou-se desenvolver o trabalho em equipe e a autonomia dos alunos e foi proposto que eles confeccionassem jogos didáticos a partir do fornecimento de materiais de baixo custo: papel cartão, tesoura, cola, EVA, canetinhas coloridas, régua e material impresso. Os jogos didáticos foram adotados com intuito de que os alunos aprendessem os conteúdos de misturas e tipos de mistura (homogênea, heterogênea), métodos de separação de mistura e coleta seletiva. Neste mesmo momento disponibilizamos antes da finalização e conclusão dos jogos um questionário de avaliação diagnóstica do tipo semiaberto com questões abertas e fechadas para coletar o conhecimento que eles estavam adquirindo enquanto pesquisava para montar os jogos. Ainda nesta etapa de acompanhamento, quando houve a finalização dos jogos, observamos as apresentações e as aplicações dos jogos entre os grupos e foram feitas entrevistas com os grupos. Sendo que neste primeiro momento foi necessário utilizar seis aulas de química.

Segundo momento pedagógico

No segundo momento foram trabalhadas a habilidade para resolver problemas e a consciência ambiental dos alunos. Para tanto, foi elaborado um estudo de caso próprio baseando-se na situação do lixo espalhado no espaço de vivência da escola, intitulado de "coleta seletiva".

Também foram utilizados outros casos prontos adaptados de um trabalho de atividades diferenciadas de Vieira (2014), que relataram problemas como: contaminação da água, escassez, água barrenta, poluição e problemas dos esgotos sem tratamento. Os casos foram entregues a cada grupo de alunos, em apenas duas aulas de química, e foi observado como os estudantes se articulavam para resolver cada situação problema.

Terceiro momento pedagógico

A metodologia deste momento envolveu uma atividade educativa em um espaço não-formal de ensino. Foi realizada uma visita à estação de tratamento de água (ETA) da cidade, devido os conteúdos das disciplinas abordarem a temática sobre as etapas ou métodos do tratamento da água. Este momento precisou de três aulas de química, pois os 45 alunos da turma foram divididos em 3 grupos. Enquanto um grupo de alunos estava na visita, o outro grupo estava pesquisando o tratamento da água em outras regiões. Neste mesmo momento também foi aplicado um questionário do tipo semiaberto para coletar o aprendizado desses alunos, com o 
intuito de verificar o que eles realmente aprenderam. Para finalizar, em outras 2 aulas, os alunos construíram, em grupos, um sistema de filtração simples com materiais de baixo custo: garrafa pet, carvão, areia, algodão, cascalhos e água barrenta.

\section{Quarto momento pedagógico}

No quarto e último momento, foi trabalhado a investigação de soluções de problemas. Neste momento, foram realizadas aulas de experimentações investigativas com a utilização de 12 aulas, aplicando três tipos de investigações. Por exemplo, a investigação 1 "como diferenciar um refrigerante com açúcar de sua versão zero" e a investigação 2 "como descobrir se uma moeda é de bronze" e a investigação 3 "como é possível quantificar o soluto presente em uma solução aquosa". No caso da investigação 3, foram abordados a massa de um soluto e o volume de uma solução (NUNES e MOTOKANE, 2017).

As experimentações investigativas foram realizadas por etapas, no início foi aplicado um questionário diagnóstico individual, com objetivo de avaliar o nível de conhecimentos prévios de cada aluno. Em seguida, foi entregue individualmente um texto de investigação sugerindo que cada aluno formulasse uma hipótese para a pergunta. Neste mesmo material continha uma lista de utensílios disponíveis para o uso ou não no experimento de investigação. A cada aula experimental eram formados grupos diferentes e entre si discutiam e decidiam qual a melhor hipótese para ser colocada em prática experimental. Em conclusão, após cada aula experimental, antes de iniciar a próxima os alunos individualmente respondiam o questionário de satisfação.

\section{Resultados e Discussão}

No primeiro momento pedagógico os jogos didáticos trabalhados com os alunos promoveram o aprendizado dos conceitos de misturas e tipos de misturas (homogênea e heterogênea) e técnicas de separação de mistura. Foi observado que, quando os alunos receberam a proposta para construírem os jogos didáticos, alguns grupos foram para biblioteca para pesquisar, outros grupos ficaram no espaço de vivência da escola pesquisando com o celular e os demais grupos resolveram continuar em sala e utilizaram o celular para pesquisar. Os jogos ficaram a critério de cada grupo, sendo que eles pesquisaram vários tipos de jogos e cada grupo escolheu um modelo de jogo, alguns grupos somente adaptaram ou modificaram um jogo já existente. As perguntas para os jogos foram eles que formularam, mas houve grupos que pegaram perguntas já prontas no momento da pesquisa. Haviam jogos que continham regras e objetivos a serem cumpridos. Os grupos confeccionaram jogos do tipo modelo de trilha, 
baralho, cartas, memória e etc. Os jogos foram classificados como: jogos cognitivos, competitivos, cooperativos, individuais em grupo, jogos de perguntas e respostas.

Observou-se muita autonomia quando os grupos pensaram no jogo didático, tanto no momento de decidir qual tipo de jogo deveria ser feito como na elaboração das perguntas para os jogos didáticos e as regras. Verificou-se que aprenderam melhor os conteúdos e isso foi notável ao responderem o questionário diagnóstico quando foi perguntado o que eles entendiam sobre mistura e se conseguiriam diferenciar e dar exemplos de mistura homogênea e heterogênea. Afinal, 32 alunos responderam corretamente e 11 alunos deram resposta incompleta. A avaliação dos jogos foi feita por meio da observação, grupo por grupo, no momento que jogaram/trocaram os jogos entre si e também usando alguns critérios como criatividade, o empenho e o que conseguiram aprender com a metodologia de jogos. Para finalizar, cada aluno fez uma auto avaliação, relatando o quanto aprenderam com a metodologia de jogos. A seguir exemplificamos uma auto avaliação da aluna $\mathrm{X}$ do $1^{\circ} \mathrm{A}$, demonstrada na Figura 1.

Figura 1 - Relato de uma auto-avaliação de uma aluna $\mathrm{X}$ do $1^{\circ} \mathrm{A}$

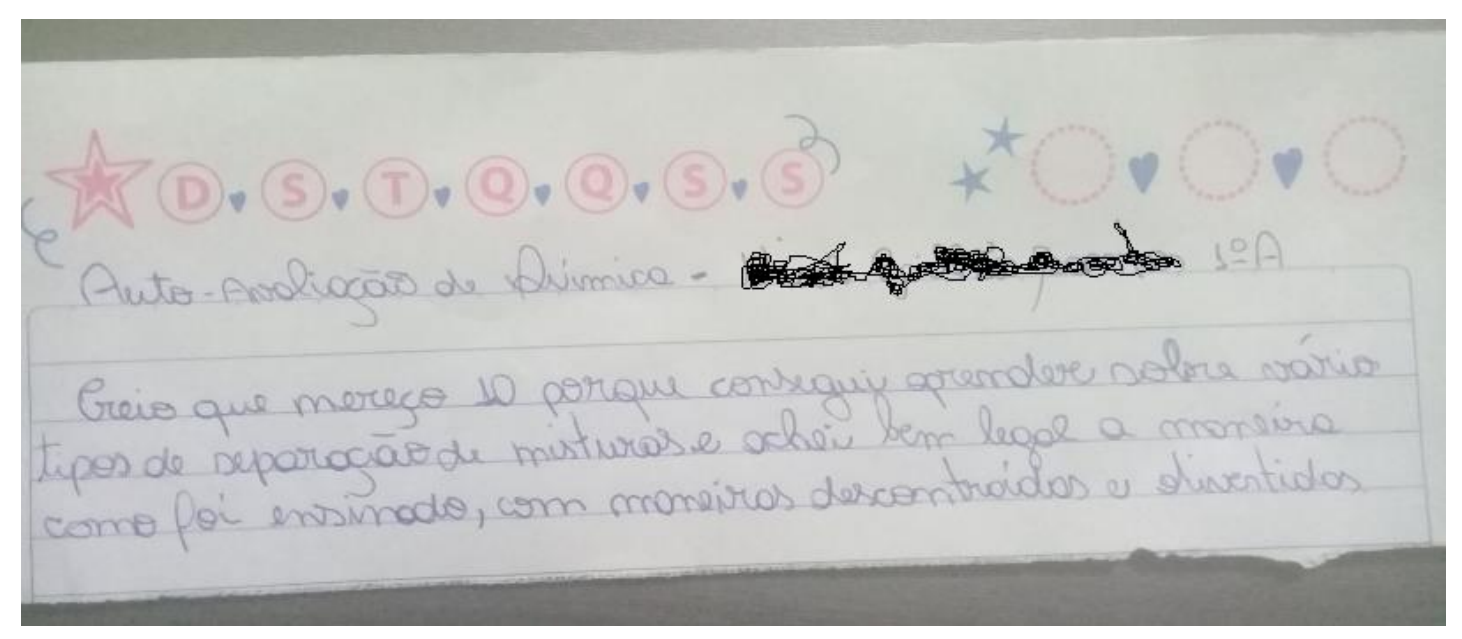

Fonte: Própria (2018)

Como exemplo, a Figura 2 ilustra imagem de um dos jogos de 15 cartas de pergunta e resposta, feito por um grupo de alunos. Nas regras deste jogo constavam que devia ser jogado em grupo ou dupla, sendo que o aluno escolhe uma carta e tem que responder a pergunta corretamente. Conseguindo responder ele tinha direito a pegar outra carta e se errasse passava a vez a outro participante até que terminassem todas as cartas. Ganhava o jogo quem respondia mais perguntas. Ao final de cada apresentação dos jogos por equipe foram feitas perguntas para 
verificar se eles já tiveram contato com jogos como meio de aprender algum conteúdo; se houve dificuldade para pensar na elaboração dos jogos, nas perguntas e respostas acerca do conteúdo e se estavam conseguindo aprender com essa metodologia de jogos. As respostas dos noves grupos referente às perguntas acima foram: que não tiveram experiências com jogos didáticos na antiga escola; os únicos jogos que jogaram foram somente para se divertir e não tinham uma finalidade de aprender determinado conteúdo, exceto um grupo que respondeu que jogaram um jogo com a finalidade de aprender tabuada; que nunca elaboraram um jogo; que sempre que jogaram para se divertir acharam jogos prontos; que percebem que estão aprendendo, pois para elaborar o jogo foi preciso pesquisar; que está ocorrendo o aprendizado, pois querem ganhar o jogo; que gostam da metodologia de jogos no ensino de Química para aprender.

Figura 2 - Uma carta do modelo de um jogo de perguntas e respostas confeccionado por um grupo de alunos (a)

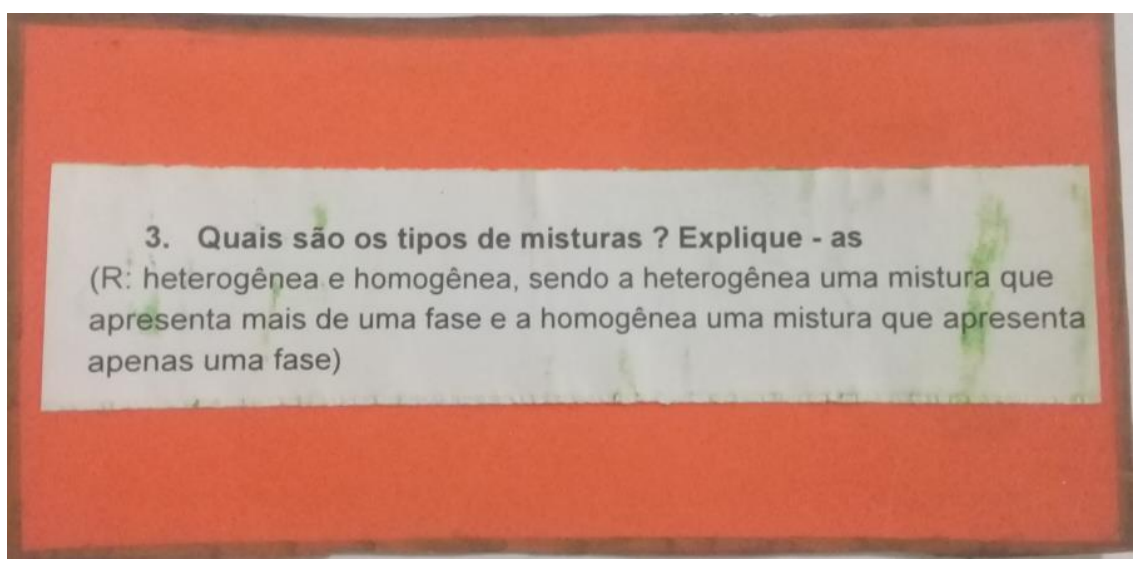

Fonte: Própria (2018)

Quando foi questionado aos 43 alunos se eles praticam e sabem "o que é coleta seletiva", na avaliação diagnóstica antes de jogarem/apresentarem os jogos, percebe-se que mais da metade dos alunos têm conhecimento do assunto e praticam, conforme mostrado na Figura 3, enquanto que a minoria não pratica, e há outros que desconhecem o assunto abordado e outros que afirmaram não praticar mesmo conhecendo o assunto.

Figura 3 - Questionário de avaliação diagnóstica conceito de coleta seletiva 


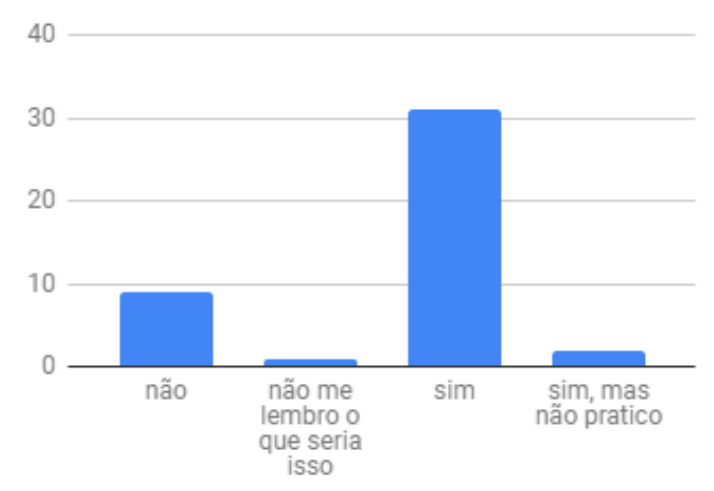

Fonte: Própria (2018)

No segundo momento pedagógico, promoveu-se o trabalho em equipe e a habilidade para resolver problemas do cotidiano. Após a leitura dos quatro casos, os grupos discutiram entre si qual seria a melhor solução para cada situação problema. Observamos algumas habilidades que foram exercitadas no momento em que eles buscaram solucionar os casos. Nesse sentido, eles desenvolveram habilidades para lidarem com situações problemas, quando solucionam e apresentaram as soluções dos casos e deram sugestões para o problema do lixo no espaço de vivência do câmpus.

“Esta situação pode ser melhorada podendo fazer palestra, eventos, alertando os alunos e quanto mais ajudantes para espalhar sobre a reciclagem melhor será. Vamos fazer uma reunião com cada representante de sala para conversarmos sobre o destino do lixo produzido dentro da escola seria bom também se fizessem um projeto sobre coleta seletiva'’(ALUNOS A, B, I).

Consequentemente, houve um fortalecimento no trabalho em equipe, para ler e resolver cada caso. Inclusive aprenderam a pesquisar para resolver os problemas. Ficou evidente que houve uma melhora na comunicação escrita e oral destas alunas e isso pode ser observado nessa solução dada para o problema de uma fábrica que após se instalar próximo a comunidade de Santo Amaro do Maranhão estava poluindo o rio que produzia o sustento para aquela população local.

Olá P. H. H.

Através deste email, iremos os auxiliar nesse projeto. Bom, geralmente para despoluir um rio, o primeiro passo é garantir que nenhum esgoto seja lançado sem o devido tratamento nas águas. Para isso, é essencial o investimento em novas estações de tratamento. Além de tratar o esgoto lançado, é importante criar campanhas de conscientização da população, de indústrias, etc, para que nenhum material seja lançado. Atenciosamente alunas ...! (ALUNAS J, K).

Percebeu-se que estavam mais desinibidos quando apresentaram a solução para o caso intitulado "Comunidade da Praia de Massarandopió" sobre a falta de água potável no nordeste 
conforme citação de um grupo de alunos.

Olá, é possível sim através de um processo chamado dessalinização, o qual abrange diversas técnicas. A mais bem sucedida é a chamada osmose inversa, que separa o líquido por meio de um plástico poroso que barra os sais. Mas também há outros tipos de técnicas como: evaporação pioneira e poros purificadores. Este processo chamado osmose inversa funciona da seguinte maneira: a água que vem do mar é dividida por centena de cilindros, cada um possui membranas plásticas que separam a água potável do sal. O custo deste processo em média é de R \$ 2,55 para $1 \mathrm{~m} 3$ de água salgada, que equivale a 1 mil litros, para transformá-la em água doce. Podemos ajudar fazendo no laboratório químico por destilação simples, onde colocamos água salgada num balão de destilação e o aquecemos. Por meio da fervura a água evapora e passa por um condensador que está sendo resfriado por água corrente. Assim o vapor d'água condensa voltando ao estado líquido e sendo coletado na saída do condensador, enquanto o sal fica preso no balão de destilação. Atenciosamente, alunos ... (ALUNOS B, G, I).

Da mesma forma, adquiriram grande facilidade para argumentar, diante dos questionamentos para solucionar o problema proposto no interior do rio Amazonas sobre a qualidade da água que a população daquele lugar estava utilizando para o consumo, pois era muito suja e com muito barro.

“'Olá M. V. e a todo o Jornal A Pesquisa,

Agradecemos desde já a consideração e a confiança. Porém, acredito que já cansou-se de ouvir que a maneira mais eficaz de recuperar um rio poluído é coletar o lixo, afastá-lo e tratar os esgotos. Pois bem, esse processo é o mais aceitável para uma grande extensão de água, mas convenhamos... é demorado e cansativo, sendo uma maneira lenta e progressiva de se despoluir. Mas, como é necessário um modo inteligente para que essa água seja consumida e esse rio volte a ser utilizado, preparamos diversas opções. Sendo elas, com um nível superficial de limpeza ou com grande intensidade da mesma porém com um longo processo e tempo.

Poderíamos sugerir a autodepuração para o auxílio da solução desse problema, mas como tantas outras opções, é um procedimento lento e que pode levar anos. Mas, para interesse do próprio cidadão, pode-se utilizar o processo de filtração de uma certa quantidade de água para que esta seja consumida. A construção de um filtro caseiro é uma boa solução para o ambiente familiar que tem carência de água limpa e potável...

... Mas ainda sim, a implantação de medidas definitivas para a recuperação desse rio é necessário e inevitável, já que filtros caseiros são apenas uma solução temporária e não confiável. Igualmente como a coleta de todo o lixo superficial que boia pelo rio e o ato de tirar as fontes que despejam esse lixo (tubos de esgoto, por exemplo). No entanto, nada disso fará sentido se a comunidade não se conscientizar, todos precisam ter responsabilidade com seu lixo e empatia para que não o despeje no rio, ainda mais que as consequências se tornam severas e prejudicam o próprio consumo da água..." (ALUNAS I, J, M).

A Figura 4 demonstra o momento que um grupo de alunos recebem as primeiras 
informações a respeito do manancial que o ETA capta a água para o tratamento. Logo mais adiante eles conheceram todas as etapas do tratamento que aquela água passou antes de chegar às residências.

Figura 4 - Um grupo de alunos na estação de tratamento de água de Capivari (ETA)

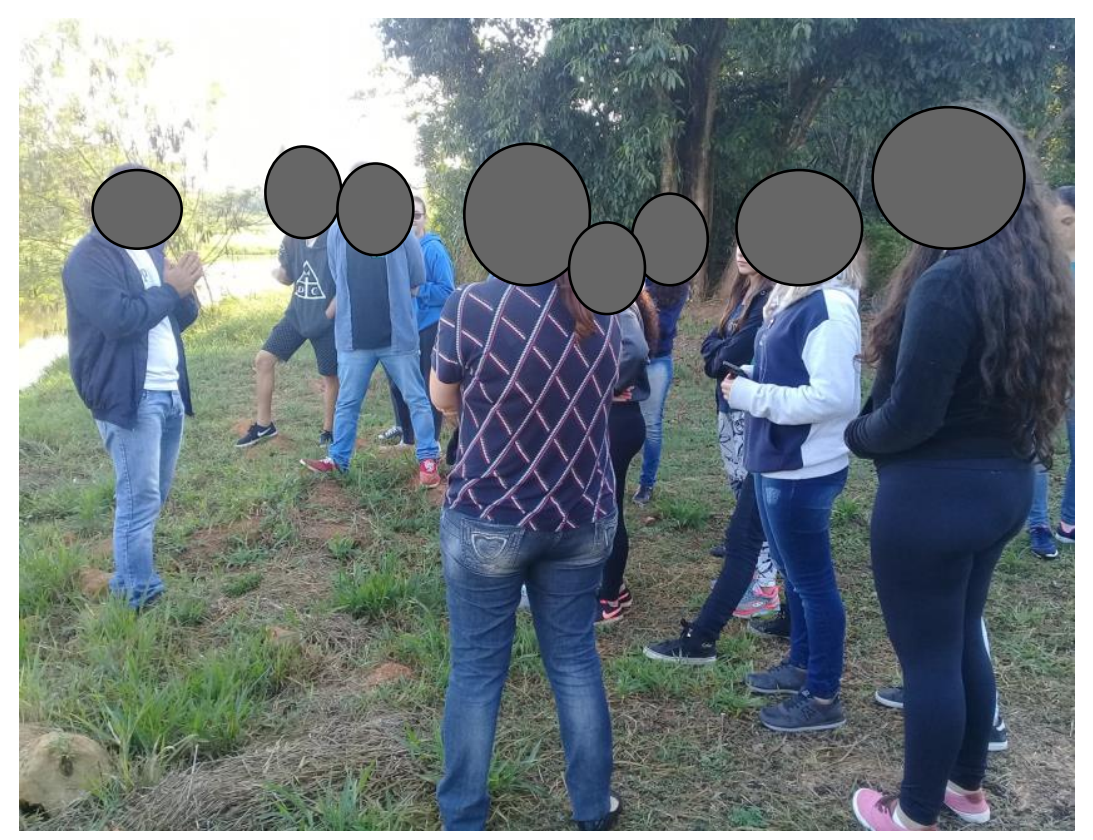

Fonte: Própria (2018)

Após a realização da visita técnica, pode-se perceber a melhor apreensão, pelos estudantes, da importância e entendimento dos processos de tratamento de água para o consumo urbano. Inclusive, este fato pode ser verificado, ao responderem o questionário da visita técnica. Uma vez que aprenderam na prática o processo do tratamento da água. A propósito, aprenderam a pesquisar melhor, pois verificaram sobre outras estações de tratamentos de água de região próxima e compararam com o ETA.

No entanto, quando foi perguntado se foi possível identificar todas as etapas do tratamento da água no momento que visitaram o ETA, os 45 alunos responderam que conseguiram identificar. Em outra questão, foi perguntado quais métodos do tratamento da água foram possíveis identificar no momento da visita, 5 alunos responderam que conseguiram identificar todas as etapas, enquanto que 38 alunos conseguiram identificar algumas etapas. Consequentemente, acredita-se que estes alunos não estavam atentos no momento da visita ou no momento de responder o questionário. 
Em vista disso, quando foi perguntado na questão 14 em qual cidade nasce o manancial que fornece água para o ETA, sendo que 79,1\% responderam corretamente na cidade de Nova Odessa, enquanto 2,3\% não responderam e 16,3\% disseram em Santa Bárbara d' Oeste e 2,3\% disseram nascer em Capivari. Por exemplo, no momento da visita o técnico do ETA alertou sobre a conscientização de todos na redução do consumo excessivo da água. Por conseguinte, quando foi perguntado na questão 9 , se eles têm praticado alguma atitude com a relação ao consumo exagerado da água, 25 alunos disseram reduzir o tempo no banho e não desperdiçar água ao escovar os dentes; 10 alunos disseram que sempre reduzem o tempo no banho; 3 alunos disseram não desperdiçarem ao escovar os dentes e que lavam o carro com balde; 5 alunos disseram que não desperdiçam água ao escovar os dentes.

Neste gráfico da Figura 5 consta que foi possível identificar todas as etapas do tratamento da água, afirmações dos alunos que participaram da visita técnica à Estação de Tratamento de Água.

Figura 5 - Se refere a pergunta do questionário da visita técnica.

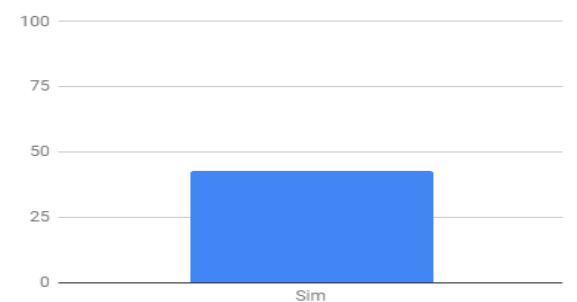

Fonte: Própria (2018)

De acordo com a Figura 6, quando foi perguntado para os alunos qual o método do tratamento da água que faz com que as sujeiras menores fiquem retidas e não passem para a próxima etapa, nota-se que 28 alunos acertaram a pergunta, enquanto 15 alunos não responderam corretamente.

Figura 6 - Se refere à questão 5 do questionário da visita técnica. 


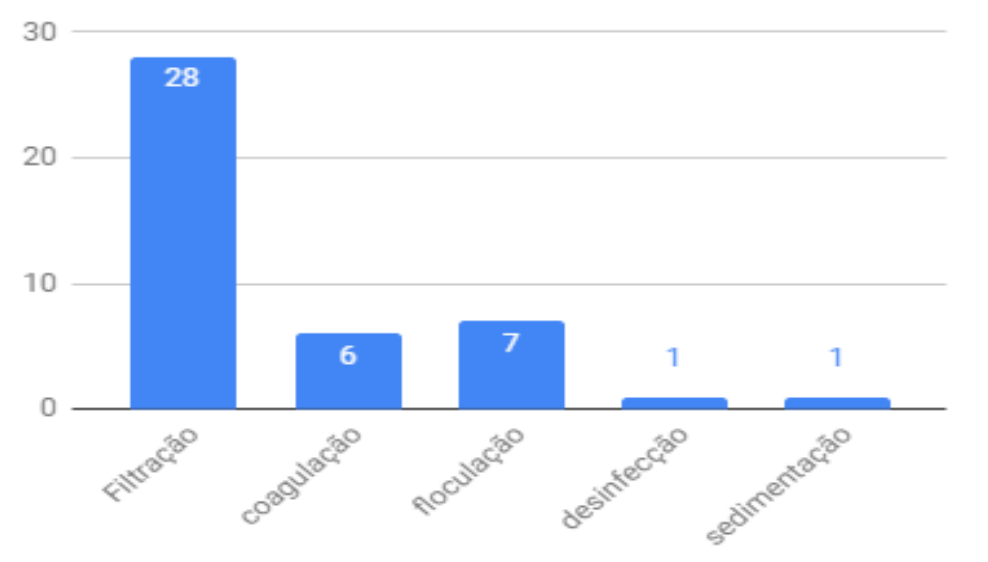

Fonte: Própria (2018)

A figura 7 ilustra um sistema de filtração simples construído por um dos grupos de alunos, este sistema fez o processo de filtração simples de separação de mistura heterogênea, isto é da água barrenta e areia. No entanto sabe-se que esta água ainda não é potável, ou seja, imprópria para o consumo. Para que água esteja totalmente apta para o consumo precisa passar por todas as etapas de tratamento. No entanto, como ainda existem lugares que não dispõem de uma estação de tratamento de água do rio, as pessoas desses lugares têm utilizado esse sistema de filtração simples em maior escala e depois fervem a água para o consumo doméstico.

Figura 7 - Aula prática elaboração de um sistema de filtração simples de água

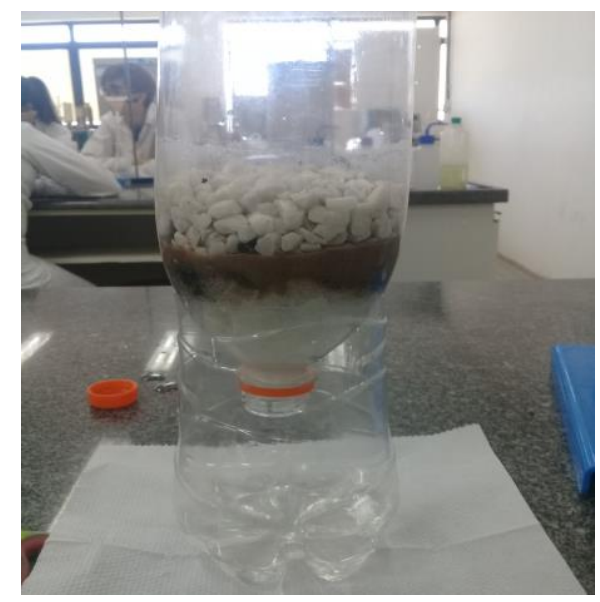

Fonte: Própria (2018)

Quarto momento da prática pedagógica experimentação investigativa

Neste momento os alunos aprimoram o entendimento da construção da ciência, pois a cada investigação o estudante se via diante de questionamentos sobre assuntos problemas. No 
entanto, diante das hipóteses formuladas pelos alunos, mais uma vez nós observamos que eles aprenderam a argumentar diante de questionamento. Por exemplo, uma das hipóteses para investigação 1, levantada por estes estudantes para identificar qual o refrigerante zero e qual o refrigerante normal pode ser observado no recorte citado da hipótese formulada pela aluna A.

"Se a composição química do refrigerante zero açúcar é diferente da composição do refrigerante original, então a densidade do refrigerante zero açúcar será diferente da densidade do refrigerante original" (ALUNA, 2018).

Segue o procedimento para investigar, que a mesma formulou para identificar qual refrigerante é o zero e qual é o normal.

"Pesar béqueres vazios em uma balança e tarar, e colocar $100 \mathrm{~mL}$ de cada refrigerantes nos béqueres e pesa-los para descobrir a massa dos refrigerantes. Calcular a densidade dos refrigerantes dividido sua massa pelo seu volume" (ALUNA, 2018).

Outra hipótese construída por um grupo de alunas foi a seguinte conforme explicitado na citação abaixo:

\footnotetext{
"Se ambos possuem constituições químicas diferentes, as densidades serão diferentes, então o refrigerante original será mais denso, pois possui gramas de açúcar e o refrigerante zero possui miligramas de educolrantes" (ALUNAS, 2018).
}

Neste momento os alunos tinham um tempo, então formavam grupos e discutiam entre si qual metodologia seria utilizada para averiguar a hipótese que foi levantada. Logo abaixo segue uma metodologia que o grupo escolheu e utilizou para trabalhar para investigar os refrigerantes.

"Usar os béqueres para medir a massa do refrigerante na balança utilizando a pipeta volumétrica e pêra de sucção, em seguida calcular massa dos dois. O mais denso será o refrigerante original. E o resultado obtido da densidade das amostras: amostra 1 igual a $0,8744 \mathrm{~g} / \mathrm{mL}$ e amostra 2 igual a 1,0318g/mL. A amostra 2 é original pois é mais densa. Elas concluiram que, que foi levada em consideração a ordem decrescente dos ingredientes em relação a quantidade. A coca original possui menos ingredientes que a coca cola zero açúcar, porém esses ingredientes possuem quantidade maiores em massas do que a coca zero, o que a torna mais densa (ALUNAS, 2018)

Em conformidade com o momento pedagógico, a investigação 2 trouxe um questionamento sobre a composição das moedas de 10 centavos e 25 centavos, descrita por um trio de alunas:

"A primeira hipótese é que se as moedas são de bronze não oxidam, e a segunda hipótese que se a moeda for de bronze deve então analisar a cor e a densidade" (ALUNAS, 2018).

Para que elas pudessem verificar as hipóteses que elas discutiram e chegar a um resultado, elas utilizaram metodologia experimental abaixo. Concluímos que elas acreditam que a moeda é de bronze, pois na tabela do texto da investigação 2 consta que a densidade da moeda de bronze de acordo com a liga é aproximadamente $8,93 \mathrm{~g} / \mathrm{mL}$.

"1 Hipótese utilizar béqueres com água e açúcar. Mergulhar as moedas e depois retira-las e 
limpá-las com palha de aço. Aquela que se manter livre de oxidação é a moeda de bronze. $2^{\circ}$ Hipótese pesar-se as moedas na balança para descobrir suas massas. Utilizou-se a pipeta volumétrica e a proveta para definir o volume. Descobrindo densidade descobrir-se a liga do material. Resultados obtidos: massas das moedas 48,100g, 4,095g e 48,102g com média de $48,099 \mathrm{~g}$. Pipetou-se $25 \mathrm{~mL}$ para a proveta de $27 \mathrm{~mL}$. O volume foi para $33 \mathrm{~mL}$ depois que colocou as moedas subindo $6 \mathrm{~mL}$ no volume. A densidade encontrada foi igual a $8,0165 \mathrm{~g} / \mathrm{mL}$. Resposta é de bronze (ALUNAS, 2018).

Do mesmo modo, na etapa de investigação 3 foi o momento de quantificar a soluto presente em uma solução. Sendo a concentração a relação que há entre a massa de um soluto e o volume da solução. Segue a maneira como essas alunas resolveram essa investigação.

"Hipótese: se conseguir separar cada componente de um sistema heterogênea, pode-se encontrar a concentração em massa" (ALUNAS, 2018).

A metodologia que essas alunas adotaram para quantificar o soluto presente na solução aquosa segue descrita logo abaixo.

"Primeiro retirar as esferas de vidro utilizando uma peneira e um béquer, em segundo verificar o volume da solução, terceiro aquecer a solução para obter somente o sal, quarto pesar o sal adquirido, quinto efetuar o cálculo utilizando a massa do soluto 5,46g e o volume da solução $50 \mathrm{~mL}$ e o resultado $0,1092 \mathrm{~g} / \mathrm{mL}$.

\section{Conclusões}

Foi possível avaliar que a aplicação das metodologias ativas foram bem aceitas pelos estudantes com base nas auto avaliações individuais realizadas ao final dos momentos pedagógicos que se referiam a aprendizagem.

Com aplicação deste projeto, conclui-se que foi perceptível a aprendizagem significativa com o uso das metodologias ativas e que essas metodologias foram consideradas positivas como apoio didático às aulas de química. Foi possível promover o aprendizado e motivação dos alunos do ensino médio, pois eles demonstraram interesse nos momentos pedagógicos e também quando passaram pelos processos avaliativos.

Por meio da aplicação deste projeto, foi possível desenvolver algumas habilidades de fundamental importância para a formação desses alunos. Percebe-se que estes alunos adquiriram mais autonomia e desenvolveram o pensamento mais crítico aos conhecimentos adquiridos.

\section{Referências}


CHARLOT, B. Formação de Professores: a pesquisa e a política educacional. In: PIMENTA, S. G. e GHEDIN, E. Professor Reflexivo no Brasil: gênese e crítica de um conceito. São Paulo: Cortez, 2002, p. 89-108.

CHASSOT, A. Alfabetização científica: questões e desafios para a educação. $2^{a}$ edição, Santa Cruz do Sul: EDUNISC, 2007.

COSTA, M. N. M. G.; ARAÚJO, R. P. A importância da visita técnica como recurso didático metodológico. Um relato na prática do IF Sertão Pernambucano. In: VII CONNEPI-Congresso Norte e Nordeste de pesquisa e inovação, Palmas-TO. 2012.

CUNHA, M. B. Jogos de Química: Desenvolvendo habilidades e socializando o grupo. In: ENCONTRO NACIONAL DE ENSINO DE QUÍMICA, 12, Goiânia (Universidade Federal de Goiás; Goiás), 2004. Anais, 028, 2004.

DINIZ-PEREIRA, J. E. A pesquisa dos educadores como estratégia para construção de modelos críticos de formação docente. In: DINIZ-PEREIRA, J. E. e ZEICHNER, K. M. (Orgs.) A pesquisa na formação e no trabalho docente. Belo Horizonte: Autêntica, 2008.

ESQUILLER, M CHIRICO, J.C.; VARGAS, Y.L.C.; CASUSO, D.T.; MARTINS, J.A.S.; LIMA, L.. Jogo didático para o ensino de química-geral, Ensino médio: Projeto, produção, aplicação e avaliação. Ensino de Química. Disponível em:<http://www.abq.org.br/cbq/2015/trabalhos/6/8065-20532.html> acesso em 30/08/2019

GIORDAN, M. O papel da experimentação no ensino da ciência. Química Nova na Escola. No 10, 43-49, 1999.

FRANCISCO JR, W. E. F; FERREIRA, L. H.; HARTWIG, D. R. Experimentação Problematizadora: Fundamentos Teóricos e Práticos para a Aplicação em Salas de Aula de Ciências. Quím. nova esc., $\mathbf{N}^{\circ}$ 30, novembro 2008, p $34-41$

LIMA, E.C.; MARIANO, D.G.; PAVAN, F.M.; LIMA, A.A.; ARÇARI, D.P. Uso de Jogos Lúdicos Como Auxilio Para o Ensino de Química. Centro Universitário Amparense. UNIFIA. 2018 Disponível em:< http://quimimoreira.net/Jogos\%20ludicos\%20no\%20ensino\%20quimica.pdf> acesso em 30/08/2019

MACEDO, M. E. R; OLIVEIRA, P. S; SOUSA, I; COSTA, F. F. P; BEZERRA, G. S; AGUIAR, L. O. Jogo Lúdico como Ferramenta Pedagógica no Ensino de Química. Jogo Lúdico. VII CONNEPI. Tocantins, Palmas. 2012

NUNES, T. S; MOTOKANE, M.T. Análise de hipóteses escritas na solução de problemas em sequências didáticas investigativas. Revista de Educación en Biología. Universidade de São Paulo. Faculdade de Filosofia, Ciências e Letras de Ribeirão Preto. Vol. 20 No 1 p 72-86. 2017.

PERON, C et al. O uso da experimentação como estratégia didático-pedagógica para o ensino de química. Experimentação no Ensino. Grupo de Pesquisa em Química (GPQ), 
Departamento de Ciências Exatas e da Terra, URI-Campus Frederico Westphalen, RS, Brasil. XVIII Encontro Nacional de Ensino de Química (XVIII ENEQ) Florianópolis, SC, Brasil-25 a 28 de julho de 2016. Disponível em: $<$ http://www.eneq2016.ufsc.br/anais/resumos/R11051.pdf> acesso em 30/08/2019.

PIERINI, M. F.; ROCHA, N. C.; SILVA FILHO, M. V.; CASTRO, H. C.; LOPES, R. M. Aprendizagem Baseada em Casos Investigativos e a Formação de Professores: O Potencial de Uma Aula Prática de Volumetria para Promover o Ensino Interdisciplinar. Quím. nova esc., v.37, n.2, p.112-119, Maio 2015.

SÁ, L. P; QUEIROZ, S. L. Estudo de Casos no Ensino de Química. Campinas. SP. $2^{\circ}$ ed. Revisada. Editora Átomo, 2010.

SANTOS, W. L. P. S; MALDANER, O. A. Ensino de Química em Foco. Coleção Educação Química, Ed. Unijuí. 2010. 368p

SILVA, R. R; MACHADO, P. F. L; TUNES, E. Ensino de Química em Foco. Experimentar sem Errar. Cap. 9.Ed. Unijuí. 2010. 231-260p. Coleção Educação Química

SCHNETZLER, R. P. Alternativas didáticas para a formação docente em química. In: DALBEN, A. et al. (Coords.). Coleção didática e prática de ensino. Belo Horizonte: Autêntica, 2010.

SOUZA, F. L.; AKAHOSHI, L. H.; MARCONDES, M. E. R.; DO CARMO, M. P. Atividades Experimentais Investigativas no Ensino de Química. CETEC. Capacitações. Almério Melquíades de Araújo. Unidade de ensino Médio e técnico grupo de Capacitação técnica, Pedagógica e de gestão - Cetec Capacitações. Imprensa Oficial do Estado de São Paulo. Projeto de formação continuada de professores da educação profissional do Programa Brasil Profissionalizado - Centro Paula Souza - Setec/MEC, 2013.

VIEIRA, V. V.; BRAIBANT, M. E. F; MIRANDA, A. C. G.. Estratégias Metodológicas Diferenciadas para o Ensino de Separação de Misturas. Inovação no Ensino de QuímicaMetodologias, Interdisciplinaridade e Politecnia. Universidade de Santa Cruz do Sul. $34^{\circ}$ EDEQ. p 285-292, 2014. 